\title{
Ovarian cycle of southern brown howler monkey (Alouatta guariba clamitans) through fecal progestin measurement
}

\author{
Thiago Silvestre ${ }^{1,2}$ (I) $\cdot$ Eveline S. Zanetti $^{3} \cdot$ José M. B. Duarte $^{3} \cdot$ Fernando G. Barriento $^{1}$ • \\ Zelinda M. B. Hirano ${ }^{2,4} \cdot$ Júlio C. Souza Jr. ${ }^{2,4} \cdot$ Fernando C. Passos ${ }^{1}$
}

Received: 8 August 2015/Accepted: 31 July 2016/Published online: 19 August 2016

(C) Japan Monkey Centre and Springer Japan 2016

\begin{abstract}
The ovarian cycle in howler monkeys (genus Alouatta) has beean investigated through several biological parameters (ranging between 16.3 and 29.5 days); however, no data exist concerning the ovarian activity of the southern brown howler monkey (Alouatta guariba clamitans). This study aimed to describe the ovarian cycle of $A$. g. clamitans by profiling fecal progestin concentrations. Over 20 weeks, fecal samples of eight captive adult females of A. g. clamitans were collected. The collections were made at dawn, 5 days a week, and the samples were frozen immediately following collection. Next, they were dried, pulverized and hormonal metabolites were extracted to determine progestin concentrations by enzyme immunoassay. Of the 758 samples tested, the mean concentration of fecal progestins was $2866.40 \pm 470.03 \mathrm{ng} / \mathrm{g}$ of dry feces, while the mean concentration at baseline was $814.47 \pm 164.36 \mathrm{ng} / \mathrm{g}$ of dry feces. Among the eight females, one showed no ovarian cyclicity and three presented periods of probable absence of cyclicity and low progestin concentrations. A mean duration of $16 \pm 0.52$ days was observed for the 35 cycles studied. The interluteal phase lasted $4 \pm 0.37$ days on average,
\end{abstract}

Thiago Silvestre

emaildosilvestre@gmail.com

1 Programa de Pós-Graduação em Zoologia, Departamento de Zoologia, Universidade Federal do Paraná, Curitiba, Brazil

2 Centro de Pesquisas Biológicas de Indaial, Indaial, Brazil

3 Núcleo de Pesquisa e Conservação de Cervídeos, Departamento de Zootecnia, Universidade Estadual Paulista, Jaboticabal, Brazil

4 Departamento de Ciências Naturais, Universidade Regional de Blumenau, Blumenau, Brazil with a mean concentration of fecal progestins of $467.98 \pm 29.12 \mathrm{ng} / \mathrm{g}$ of dry feces, while the luteal phase lasted $11 \pm 0.50$ days, with a mean concentration of $4283.27 \pm 193.31 \mathrm{ng} / \mathrm{g}$ of dry feces. Besides describing the characteristics of the ovarian cycle, possible causes for the low concentrations of fecal progestins and periods of absence of cyclicity are also discussed.

Keywords Howler - Fecal progestins - Reproduction . Noninvasive method $\cdot$ Ovulatory period

\section{Introduction}

The ovarian cycle in howler monkeys has been investigated through their sexual behavior, morphological changes and vaginal cytology and ranges from 16 to 20 days (Colillas and Coppo 1978; Glander 1980; Crockett and Sekulic 1982; Kugelmeier et al. 2011). However, the concentration of fecal metabolites of the sex steroids has established itself as an effective tool in monitoring and as a clearer mode of understanding the reproductive physiology in both captive and free-living primates, precisely because it permits assessment of physiological parameters in a noninvasive manner (Heistermann et al. 2001; Brown 2008; Van Belle et al. 2009; Kugelmeier et al. 2011; Van Belle 2015).

Recently, Herrick et al. (2000) estimated the ovarian cycle of A. seniculus as 29 days by determining urinary metabolite concentrations. Fecal metabolite concentrations were also used to estimated the cycles of A. caraya, at around 19 days (Kugelmeier et al. 2011), and A. pigra, at around 18 days (Van Belle et al. 2009). The data available for both fecal and urinary metabolites indicate that the follicular phase for the genus corresponds to half the length 
of the ovarian cycle (Herrick et al. 2000; Kugelmeier et al. 2011).

Currently, no data exist concerning the ovarian activity of the southern brown howler monkey (Alouatta guariba clamitans). This information enables future projections about the viability of primate populations (Kleiman and Rylands 2008) and are relevant to both in situ and ex situ conservation and management proposals (e.g. fertility studies, assisted reproduction, mating and demographic strategies). This study represents the first report aiming to validate the measurement of fecal progestogens for reproductive monitoring of the species and describe the ovarian cycle of southern brown howler monkeys by profiling fecal progestin concentrations.

\section{Methods}

\section{Study site and captive conditions}

The research was conducted between February 8, 2011 and June 25,2011 in the municipality of Indaial $\left(26^{\circ} 54^{\prime} \mathrm{S}\right.$, $49^{\circ} 23^{\prime} \mathrm{W}$ ), Santa Catarina, Brazil, specifically at the Indaial Biological Research Center (Centro de Pesquisas Biológicas de Indaial, CEPESBI)_Bugio Project. The center maintains a scientific maintenance program of wild animals (IBAMA registration no. 1/42/98/000708-90), where 41 specimens of $A$. g. clamitans are housed.

Feeding was distributed in six daily meals consisting of domestic cultivar fruits and vegetables, maintenance dog ration, Cecropia glaziovii (embaúba) and Sechium edule (chayote) leaves collected in native forest, and water provided ad libitum. The howler monkeys were exposed to natural fluctuations in the photoperiod while maintained in open enclosures measuring $3.0 \times 3.0 \times 2.6 \mathrm{~m}$ (width $\times$ length $\times$ height) that included a covered area of containment/isolation and was enriched with wide strips of water hose, stumps, food platforms and food.

\section{Animals and sample collection}

Over a 20-week period, fecal samples of eight adult females were collected (Table 1). Females 6 and 7 were originally housed in another enclosure belonging to the Bugio Project and were transferred to the CEPESBI in early March, when they became part of this experiment, such that their fecal samples were only collected for 15 weeks. The enclosures disposal was linear, alternating male and female (Table 1). Their boundary were composed of fences with large spaces that allowed contact between howlers.

Fecal sample collection was performed once a day, 5 days a week, at dawn. In order to avoid the risk of collecting samples from the previous day and/or the monkeys defecating on the samples, the enclosures were cleaned regularly and any feces accumulated during the evening period were removed at dusk, prior to the early morning collections. In the case of dyads, the individual howlers were separated (led by food stimulus) at the end of each day to ensure individualization of the samples at the time of collection. Samples were not collected when the day dawned under heavy rain, when they appeared to include diarrhea or it was necessary to separate one of the monkeys for a clinical intervention.

\section{Storage of fecal samples and hormonal extractions}

Following collection, the samples were placed in plastic Ziploc bags and immediately placed in a freezer at $-20{ }^{\circ} \mathrm{C}$ in the CEPESBI. Every month the samples were transported to the city of Curitiba, Paraná, in a cooler containing ice and again stored at $-20{ }^{\circ} \mathrm{C}$ in the Department of Zoology of the Federal University of Paraná (UFPR). The samples were removed from the freezer and placed in a heater at $80{ }^{\circ} \mathrm{C}$ for $72 \mathrm{~h}$ for drying. After being dried, they were pulverized inside plastic bags using a rubber mallet and a pistil, and then homogenized. The resulting powder was placed in small plastic bottles and again stored at $-20{ }^{\circ} \mathrm{C}$.

The extractions were performed at the Deer Research and Conservation Center (Núcleo de Pesquisa e Conservação de Cervídeos, NUPECCE) of the School of Agricultural and Veterinary Sciences of São Paulo State University (FCAV-UNESP), in the city of Jaboticabal, São Paulo, Brazil. To extract the hormone metabolites, $0.5 \mathrm{~g}$ of each sample was diluted in $5 \mathrm{~mL}$ of $80 \%$ methanol pro analysis. Next, they were vortexed for $30 \mathrm{~s}$ in stirring tubes and placed on a homogenizer for $12 \mathrm{~h}$. Later, they were vortexed again for $10 \mathrm{~s}$ and centrifuged at $377 \mathrm{~g}$ for $20 \mathrm{~min}$ (Graham et al. 2001). Next, the supernatant extract was separated from the solid phase and placed in plastic tubes, which were preserved at $-20{ }^{\circ} \mathrm{C}$ until the concentration was determined.

\section{Progestin assay}

Progestin concentrations were determined by enzyme immunoassay (EIA) (Brown 2008). To achieve this, the CL425 antibody (C. Munro, University of California, Davis, CA, USA) was used. The cross-reactivity of the CL425 antibody has been described by Graham et al. (2001). Technical validation of hormonal concentrations was obtained: (1) by observing the parallel arrangement between the standard curve and the curve formed by the pool of fecal extracts prepared by serial dilution in dilution buffer $\left(R^{2}=0.97\right.$, working dilution $\left.1: 1000\right)$; (2) by 
Table 1 Captive conditions, registration data and reproductive history of the eight adult captive female Alouatta guariba clamitans in CEPESBI who constituted the experimental group

\begin{tabular}{|c|c|c|c|c|c|c|c|}
\hline Individual & Enclosure condition & $\begin{array}{l}\text { Right } \\
\text { neighbor }\end{array}$ & $\begin{array}{l}\text { Left } \\
\text { neighbor }\end{array}$ & $\begin{array}{l}\text { Estimated age } \\
\text { (years) }\end{array}$ & $\begin{array}{l}\text { Sex-age class at } \\
\text { admission }\end{array}$ & $\begin{array}{l}\text { Reproductive } \\
\text { history }\end{array}$ & $\begin{array}{l}\text { Months in current } \\
\text { enclosure }\end{array}$ \\
\hline Female 1 & Dyad with F2 & Male 1 & Male 2 & 4.5 & Infant & Nulliparous & 3 \\
\hline Female 2 & Dyad with F1 & Male 1 & Male 2 & $>6$ & Adult & Unknown* & 3 \\
\hline Female 3 & Solitary & Male 2 & Male 3 & $>7$ & Juvenile & Nulliparous & 3 \\
\hline Female 4 & Solitary & Male 4 & Male 5 & $>11$ & Juvenile & Nulliparous & 1 \\
\hline Female 5 & $\begin{array}{l}\text { Dyad with a } \\
\text { juvenile male }\end{array}$ & Male 5 & Male 6 & $>13$ & Adult & Unknown* & 1 \\
\hline Female 6 & Dyad with F7 & Male 6 & Male 7 & $>5$ & Juvenile & Nulliparous & 0 \\
\hline Female 7 & Dyad with F6 & Male 6 & Male 7 & $>11$ & Adult & Unknown* & 0 \\
\hline Female 8 & Solitary & Male 7 & Male 8 & $>6$ & Adult & Unknown* & 0 \\
\hline
\end{tabular}

${ }^{a}$ Has never given birth in captivity

significant recovery of exogenous hormones added to appropriately diluted fecal samples $(y=1.010 x+0.571$, $R^{2}=0.98$ ); and (3) by the physiological relevance of the results obtained when the different stages of the reproductive cycle were compared.

The intra- and interassay coefficients of variation (CV) were evaluated for two internal controls, with high $(\mathrm{C} 1$, with $\sim 35 \%$ binding) and low (C2, with $\sim 70 \%$ binding) hormone concentrations (1:500 dilution and 1:2000 respectively, intra-assay $\mathrm{CV}: \mathrm{C} 1=20.76 \%$ and $\mathrm{C} 2=18.28 \%$, interassay CV: $\mathrm{C} 1=19.99 \%$ and $\mathrm{C} 2=20.46 \%$, standard curve interassay $\mathrm{CV}<6.5 \%$, total of 50 plates).

\section{Data analysis}

The concentrations of progestins were expressed in $\mathrm{ng} / \mathrm{g}$ of dry feces. Descriptive statistics of the data were performed and always expressed as the mean \pm standard error of the mean (SEM). Since this study only contemplated data concerning progesterone metabolites, the phases of the ovarian cycle were denominated the interluteal and luteal phases.

The interpretation of hormone concentrations and description of the ovarian cycles were performed individually for each female. First were selected points with lowest progestins values, considered baseline of each cycle. Then the values of mean and standard deviation (SD) of the data set was obtained. The points that were above the mean value $+2 \mathrm{SD}$ were considered indicative of luteal phase, and those who were below this threshold were considered interluteal phase (Heistermann et al. 1997).

Since the fecal samples were collected only five times per week, on the days when no collections were performed, the assumed level of progestins was obtained graphically, with a dotted line connecting the two points between the collection interval. These deduced levels were assumed for all collection intervals and formed part of the calculations of ovarian cycles and its divisions (Fig. 1).

Only complete cycles were considered. The length of the cycles (in days) was defined by the interval between the first day of the interluteal phase and the last of the luteal phase. The likely day of ovulation (day 0) was considered to be the day before the first day of increased concentrations of fecal progestins (early luteal phase), since there is a delay between blood hormone secretion and its subsequent metabolism and excretion in the feces (Shideler et al. 1993; Ziegler et al. 1996, 1997; Campbell et al. 2001).

\section{Results}

We analyzed a total of 758 samples. These analyses revealed a wide range of intra and inter-individual concentrations of progestins and in relation to the baseline level obtained for each individual (Table 2).

The profiles presented clearly demonstrated patterns of the rise and fall of progestins, which allowed us to infer the ovarian cyclicity in seven of the eight females studied (Figs. 2, 3). Considering all the females studied, a total of 36 cycles were observed. However, the second cycle of F1 presented an interluteal phase of 20 days, indicating that it may have included a short absence of cyclicity period; therefore, this cycle was disregarded in the analyses.

The remaining 35 cycles presented a mean duration of $16 \pm 0.52$ days range 10-22 days). The interluteal phase lasted on average $4 \pm 0.37$ days (range 1-10 days) with a mean concentration of fecal progestins of $467.98 \pm 29.12 \mathrm{ng} / \mathrm{g}$ of dry feces. The luteal phase lasted $11 \pm 0.50$ days (range 7-17 days) with a mean concentration of $4283.27 \pm 193.31 \mathrm{ng} / \mathrm{g}$ of dry feces (Fig. 4). 
Fig. 1 Example of a description of interluteal and luteal phases, and deductive calculation between sampling intervals based on an observed cycle of Female $1 .+$ day 0 (probable ovulation); $1^{\circ}$ day above estimated basal levels; $\downarrow$ days without collect of samples; basal level (1155.11 ng/g dry feces)

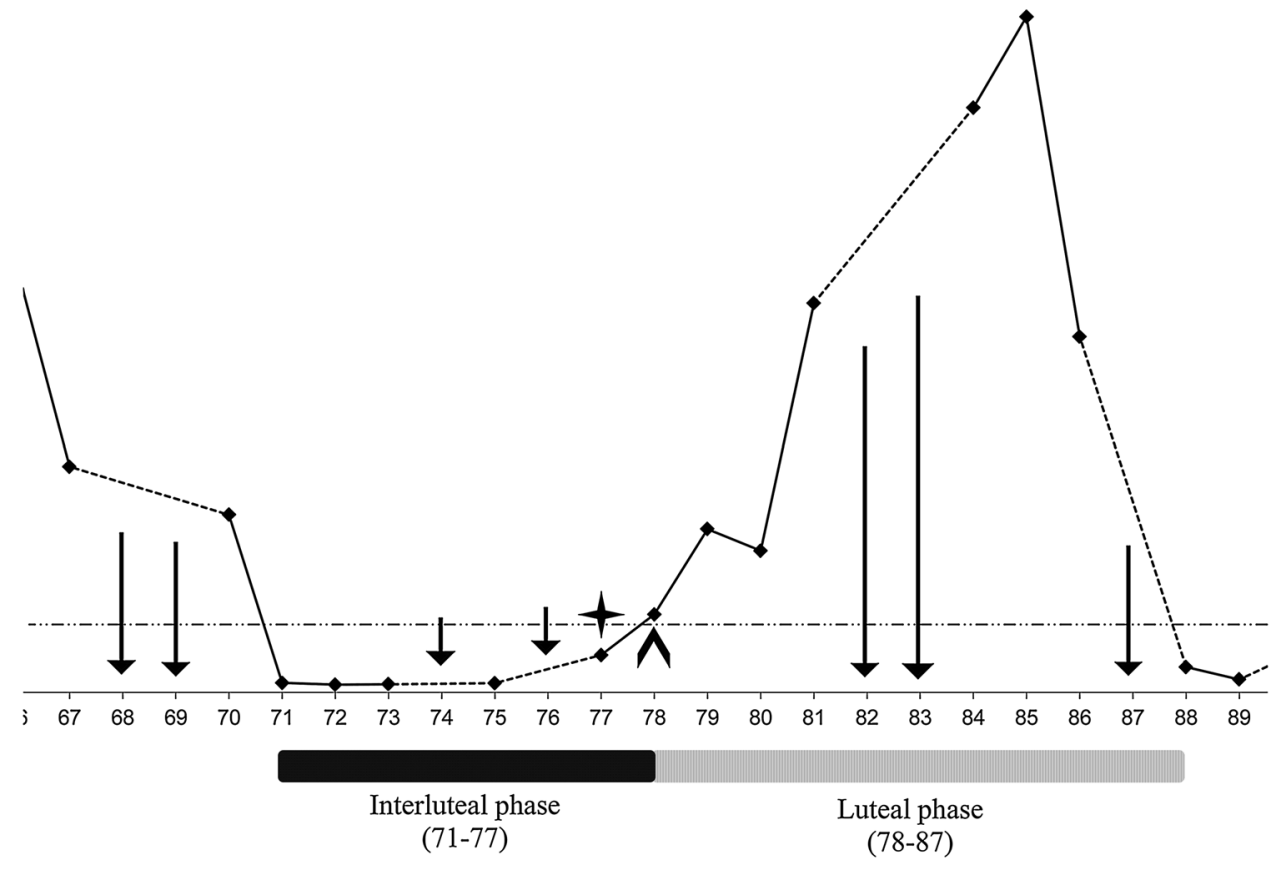

Table 2 Descriptive statistics of the concentration (ng/g dry feces) of fecal progestins of the eight captive female Alouatta guariba clamitans at the CEPESBI, who constituted the experimental group

\begin{tabular}{|c|c|c|c|c|c|c|}
\hline Individual & $\begin{array}{l}\text { Number of samples } \\
(n=748)\end{array}$ & $\begin{array}{l}\text { Mean } \\
\text { concentration }\end{array}$ & Standard error & Maximal values & Minimal values & Basal level \\
\hline F1 & 103 & 3812.16 & 470.03 & $20,859.81$ & 139.91 & 1155.11 \\
\hline $\mathrm{F} 2$ & 102 & 666.13 & 89.56 & 4412.12 & 92.72 & 193.54 \\
\hline F3 & 100 & 3622.33 & 428.30 & 19579.19 & 173.45 & 942.99 \\
\hline F4 & 100 & 3713.96 & 276.97 & 12251.48 & 243.70 & 1471.30 \\
\hline F5 & 98 & 3806.79 & 371.14 & 14390.80 & 113.78 & 399.99 \\
\hline F6 & 81 & 744.29 & 58.71 & 2684.44 & 121.59 & - \\
\hline F7 & 81 & 2348.64 & 191.92 & 9539.77 & 192.65 & 701.59 \\
\hline F8 & 93 & 3816.26 & 335.76 & $14,621.14$ & 159.45 & 836.80 \\
\hline Mean values & - & 2866.40 & 123.74 & - & - & 814.47 \\
\hline
\end{tabular}

\section{Discussion}

Measurement of fecal progestins by enzyme immunoassay demonstrated ovarian cyclicity and proved to be a reliable method of achieving this. Fecal metabolites have been measured by this method in wild Alouatta pigra (Van Belle et al. 2009) and by radioimmunoassay in captive $A$. caraya (Kugelmeier et al. 2011). In both cases, despite the availability of estrogen profiles, progestin profiles were considered more reliable for assessing ovarian cyclicity and the likely day of ovulation. These findings affirm that the ovarian cycle can be securely evaluated using only cyclic profiles of progesterone and its metabolites.

The mean length of the ovarian cycle founded in this research is the shortest described for this genus (16 \pm 0.52 days), but it is similar to data available for
Alouatta caraya and A. pigra (Van Belle et al. 2009; Kugelmeier et al. 2011) using sex steroid fecal metabolites. These results also are in agreement with descriptions of ovarian cycles for the genus using other methodologies, as well as reviewed by Van Belle (2015): vaginal cytology in A. caraya, $19.7 \pm 1$ days (Colillas and Coppo 1978), $19.8 \pm 0.9$ days (Kugelmeier et al. 2011); observation of copulations in A. seniculus, 17 days (Crockett and Sekulic 1982); and sexual behavior, together with genital morphological changes in A. palliata, $16.3 \pm 0.7$ days (Glander 1980). The only real discrepancy in the set of data presented for the genus was described by Herrick et al. (2000), who reported a mean ovarian cycle of $29.5 \pm 0.5$ days for $A$. seniculus using urinary metabolites.

When we consider the phases of the cycle, however, differences emerge. In this study, the interluteal phase 

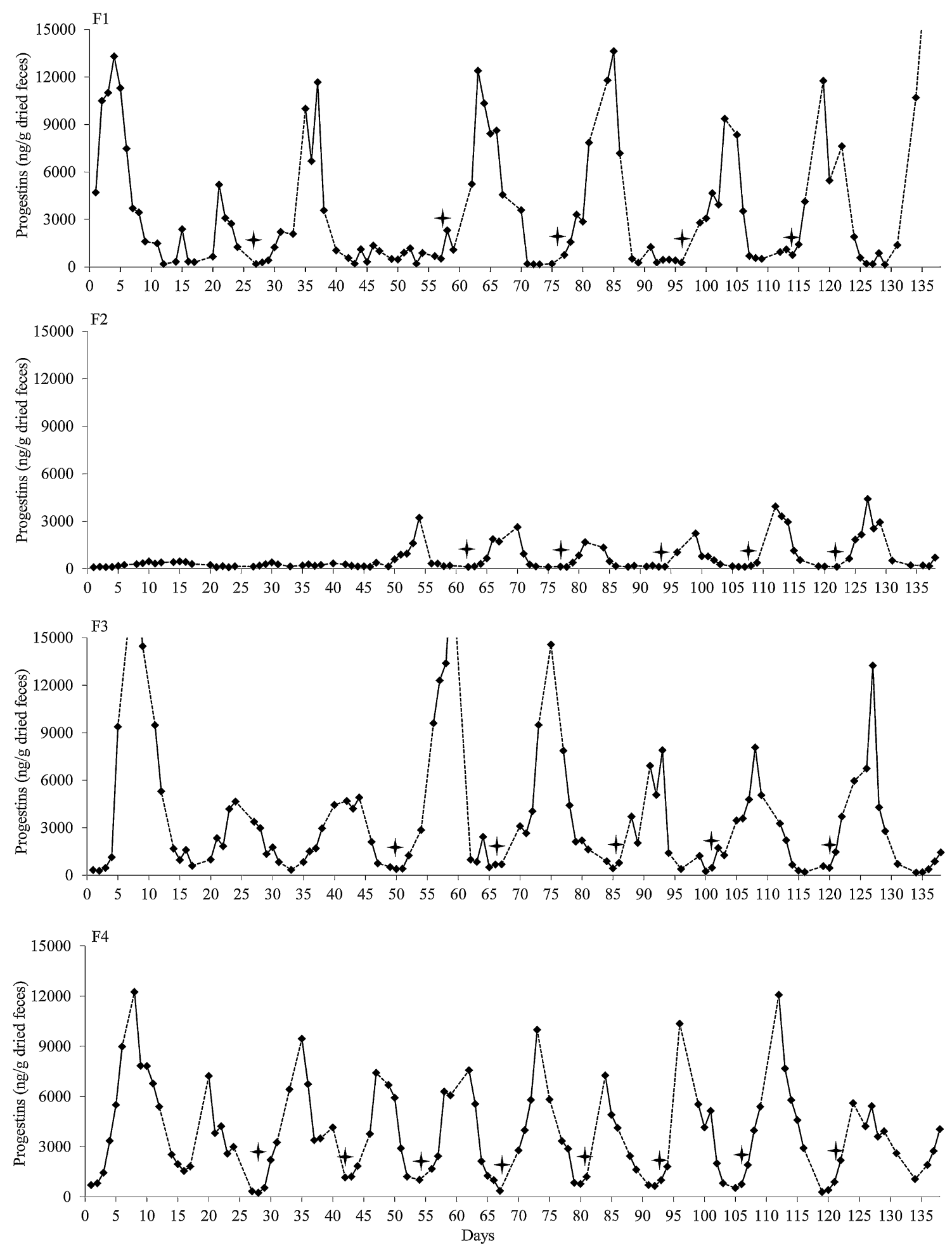

Fig. 2 Fecal progestin profiles of four female Alouatta guariba clamitans (Females 1, 2, 3 and 4) throughout the study. progestins samples; $\longrightarrow$ progestins graphically estimated; + day 0 (probable ovulation)

( $4 \pm 0.37$ days) was much shorter than the luteal phase (11 \pm 0.50 days). Kugelmeier et al. (2011) reported a nonluteal phase $(9.83 \pm 2.21$ days $)$ similar to the luteal phase (9.47 \pm 0.72 days) for Alouatta caraya. It is worth noting that it is precisely the nonluteal phase (corresponding to the interluteal phase in the methods used here) determined by the authors that showed the greatest variability on duration. 

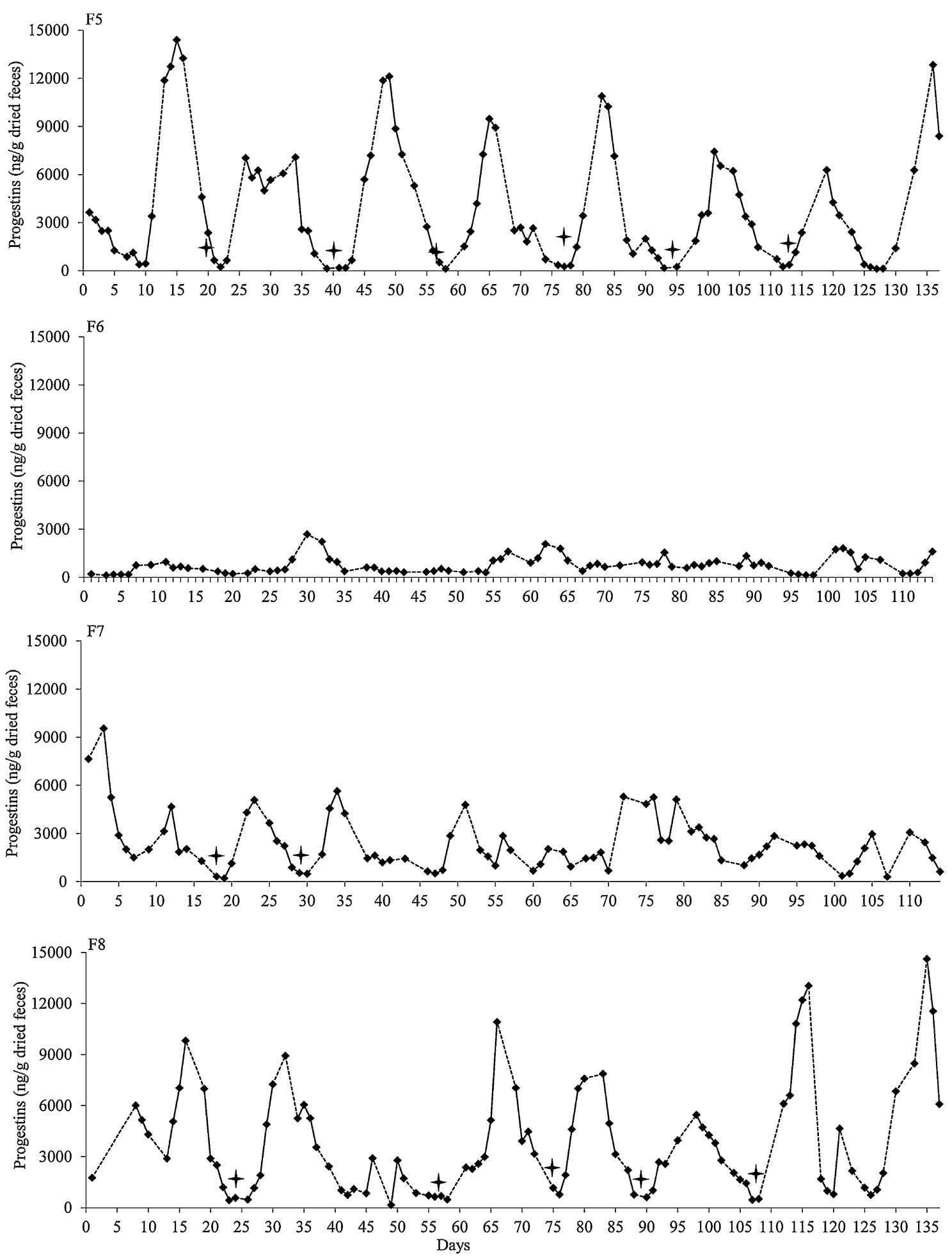

Fig. 3 Fecal progestin profiles of four female Alouatta guariba clamitans (Females 5, 6, 7 and 8) throughout the study. Progestins samples; $\longrightarrow$ progestins graphically estimated; + day 0 (probable ovulation)

Several studies show that the follicular phase, is shorter in Neotropical primates compared with Old World primates (Dixson 1983; Kendrick and Dixson 1983; Heistermann and Hodges 1995; Carosi et al. 1999; De
Vleeschouwer et al. 2000), and can last as little as 2 days in captive female Ateles geoffroyi (Campbell et al. 2001). This short length could signify that follicle maturation (ranging from 10 to 17 days in many mammals, including 


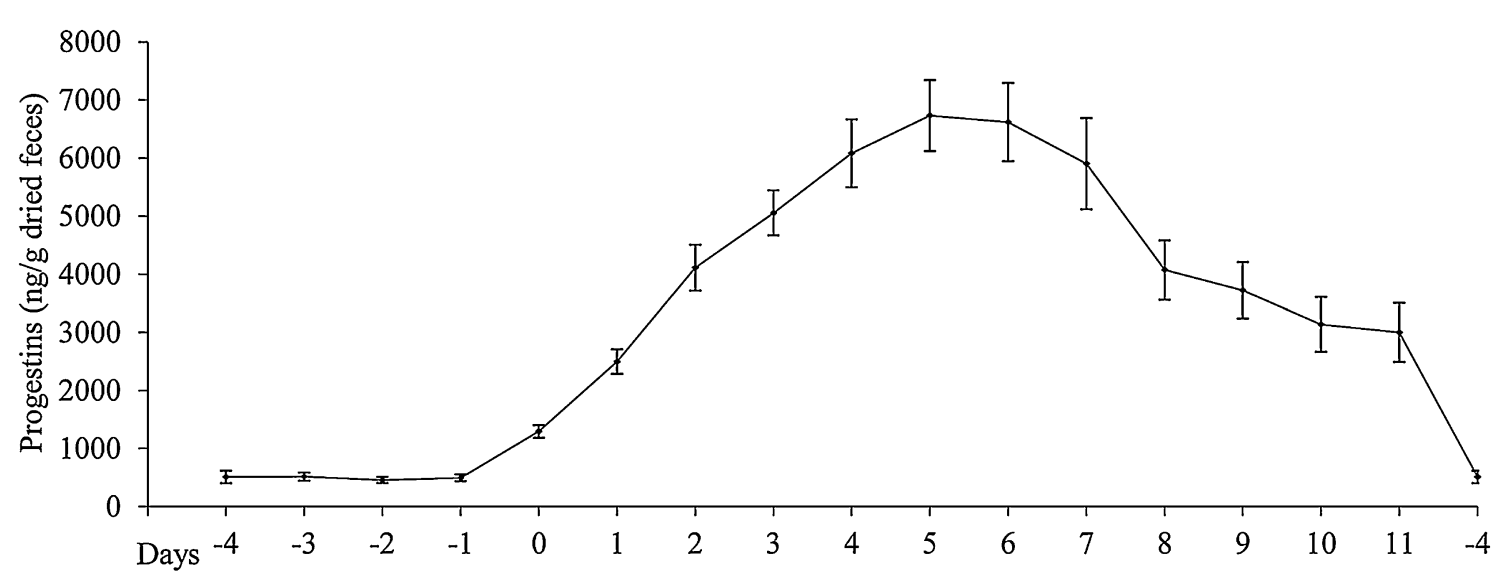

Fig. 4 Representation of the mean of the ovarian cycle of Alouatta guariba clamitans (mean \pm standard error). Normalized according Day 0, which is the onset of the luteal phase

Old World primates) occurs throughout the luteal phase. Thus the interval between the end of one luteal phase to the onset of the next could merely represent the final steps of dominant follicle maturation (reviewed in Baird et al. 1975).

Females 2, 6 and 7 showed low concentrations of progestins compared with the other females studied. This finding cannot be explained of diurnal variability in the excretion of fecal metabolites (Sousa and Ziegler 1998) or as results of a fiber-rich diet (Wasser et al. 1993), due to methodology of sample collection and standardized diet of howlers. Old age can alter ovarian activity and consequently hormone levels (Helvacioglu et al. 1994; Heistermann et al. 2001; Hernández-López et al. 2010). However this is an improbable explanation for this study, because F5 is the female who has the oldest estimated age (over 13 years-old) and was the only one to present signs of old age, such as cataracts and teeth loss. Despite this, her hormone levels and the regularity of her ovarian activity are similar to that of other females.

The regime of captivity, which involves numerous facets, both biotic and abiotic, can threaten the welfare of animals and cause stress, indicated by an increase in glucocorticoids (Morgan and Tromborg 2007; Rangel-Negrín et al. 2009; Mason 2010). The ills of chronic stress include its harmful effects on reproductive function, which can cause a reduction in progesterone levels (Sapolsky et al. 2000; Wingfield and Sapolsky 2003). The F6-F7 dyad were moved to the CEPESBI at the beginning of the study, which may have triggered stress due to physical containment, transportation and readjustment to the new environment. In particular, females of Alouatta are highly sensitive to process of handling and translocation (AguilarCucurachi et al. 2010).

Although F6 and F7 were only moved from one enclosure to another, this procedure may nonetheless have generated chronic stress for most of the study period. Female 7 had two ovarian cycles and few stereotyped behaviors (Dada et al. 2011) while F6 did not present ovarian cyclicity and presented sexual activity only 100 days after they were moved. Another piece of evidence is that she showed severe stress indicative stereotypies, including self-mutilation. In contrast, F2 did not experience ovarian cycles throughout the study period, showed no evidence of severe behavioral stress, nor did she suffer a change in enclosure prior to the study, suggesting that stress was not the main factor of her acyclicity.

Environmental factors between the postnatal development phase up to sexual maturity can be determinants for progestin levels during adulthood. Women without access to good sanitation, healthcare, stable food resources and who experience great physical stress between birth and menarche possess lower levels of salivary progestins than women who do not experience such conditions (Ellison 1996; Nuñez-de La Mora et al. 2007). Although the hypothesis of individual variation cannot be discarded, all females at CEPESBI passed through some traumatic event and analysis of their effects are impossible. The measurement of fecal glucocorticoids and longitudinal studies monitoring the behavioral and hormonal ontogeny of the howler monkeys received by the CEPESBI may clarify these unresolved issues.

In conclusion, the novel data for the species in question presented robustness that provides information concerning the reproductive physiology of Neotropical primates, while corroborating the potential of determining the concentrations of fecal progestins, a noninvasive method that assessed ovarian activity in the monkeys in this group. Moreover, it should offer insights for improving the ex situ management of the genus Alouatta, as well as providing support research on wild animals. 
Acknowledgments The authors are grateful to the Graduate Program in Zoology of the Federal University of Paraná for their support and the National Council for Scientific and Technological Development (CNPq) for providing FCP with a Grant (303757/2012-4) and TS with a scholarship (131196/2010-3). All activities of this research were conducted within the current legal norms in Brazil (Instituto Chico Mendes de Conservação da Biodiversidade License No. 26674-1) and following approval by the Ethics Committee on Animal Use of the Regional University of Blumenau, under Protocol No. 013/10.

\section{References}

Abbott DH, Hearn JP (1978) Physical, hormonal and behavioural aspects of sexual development in the marmoset monkey, Callithrix jacchus. J Reprod Fertil 53:155-166

Aguilar-Cucurachi MAS, Dias PAD, Rangel-Negrín A, Chavira R, Boeck L, Canales-Espinosa D (2010) Preliminary accumulation of stress during translocation in mantled howlers. Am J Primatol $72: 805-810$

Atsalys S, Margulis SW, Bellem A, Wielebnowski N (2004) Sexual behavior and hormonal estrus cycles in captive aged lowland gorillas (Gorilla gorilla). Am J Primatol 62:123-132

Baird DT, Baker TG, McNatty KP, Neal P (1975) Relationship between the secretion of the corpus luteum and the length of the follicular phase of the ovarian cycle. J Reprod Fertil 45:611-619

Brown JL (2008) Endocrine manual for hormonal assessment of wildlife species. Conservation and Research Center National Zoological Park, Front Royal

Campbell CJ, Shideler SE, Todd HE, Lasley BL (2001) Fecal analysis of ovarian cycle in female black-handed spider monkeys (Atelles geoffroyi). Am J Primatol 54:79-89

Carosi M, Heistermann M, Visalberghi E (1999) Display of proceptive behaviors in relation to urinary and fecal progestin levels over the ovarian cycle in female tufted capuchin monkeys. Horm Behav 36:252-265

Colillas O, Coppo J (1978) Breeding Alouatta caraya in Centro Argentino de Primates. In: Chiver DJ, Lane-Petter W (eds) Recent advances in primatology: conservation. Academic Press, London, pp 201-214

Crockett CM, Sekulic R (1982) Gestation length in red howler monkeys. Am J Primatol 3:291-294

Dada AN, Souza-Jr JC, Oliveira DAG, Hirano ZMB (2011) Padrões comportamentais de bugio-ruivo (Alouatta guariba clamitans Cabrera, 1940) em cativeiro (Primates: Atelidae). In: Miranda JMD, Hirano ZMB (eds) A Primatologia no Brasil (12). UFPR/ SBPr, Curitiba, pp 137-159

De Vleeschouwer K, Heistermann M, Van Elsacker L, Verheyen RF (2000) Signaling of reproductive status in captive female goldenheaded lion tamarins (Leontopithecus chrysomelas). Int $\mathrm{J}$ Primatol 21:445-465

Dixson AF (1983) The owl monkey. In: Hearn JP (ed) Reproduction in new world primates: New models in medical sciences. MTP Press Limited, Lancaster, pp 69-114

Ellison PT (1996) Developmental influences on adult ovarian hormonal function. Am J Hum Biol 8:725-734

Glander KE (1980) Reproduction and population growth in freeranging mantled howling monkeys. Am J Phys Anthropol $53: 25-36$

Graham LH, Schwarzenberger F, Möstl E, Galama W, Savage A (2001) A versatile enzyme immunoassay for the determination of progestogens in feces and serum. Zoo Biol 20:227-236

Heistermann M, Hodges JK (1995) Endocrine monitoring of the ovarian cycle and the pregnancy in the saddle-back tamarin
(Saguinus fuscicollis) by measurement of steroid conjugates in urine. Am J Primatol 35:117-127

Heistermann M, Trohorsch B, Hodges JK (1997) Assessment of ovarian function in the African elephant (Loxodonta africana) by measurement of $5 \alpha$-reduced progesterone metabolites in the serum and urine. Zoo Biol 16:273-284

Heistermann M, Uhrigshardt J, Husung A, Kaumanns W, Hodges JK (2001) Measurement of faecal steroid metabolites in the liontailed macaque (Macaca silenus): a non-invasive tool for assessing female ovarian function. Primate Rep 59:27-42

Helvacioglu A, Aksel S, Yeoman RR, Williams LE, Abee CR (1994) Age-related hormonal differences in cycling squirrel monkeys (Saimiri boliviensis boliviensis). Am J Primatol 32:201-213

Hernández-López L, Cerda-Molina AL, Chavira-Ramírez R, Mondragón-Ceballos R (2010) Age-dependent changes in fecal 17 $\beta$ estradiol and progesterone concentrations in female spider monkeys (Ateles geoffroyi). Theriogenology 73:468-473

Herrick JR, Agoramoorthy G, Rudran R, Harder JD (2000) Urinary progesterone in free-ranging red howler monkeys (Alouatta seniculus): preliminary observations of the estrous cycle and gestation. Am J Primatol 51:257-263

Junglos AM (2011) Funções Sociais e Ecológicas de Esfregações em Bugios-Ruivos (Alouatta guariba clamitans, Cabrera, 1940) em Ambiente Natural (dissertation). Universidade Regional de Blumenau, Blumenau, p 44p

Kendrick KM, Dixson AF (1983) The effects of the ovarian cycle on the sexual behaviour of the common marmoset (Callithrix jacchus). Physiol Behav 30:735-742

Kleiman DG, Rylands AB (2008) Biologia e conservação dos micosleões: Uma síntese e desafios para o futuro. In: Kleiman DG, Rylands AB (eds) Micos-Leões: Biologia e Conservação. MMA, Brasília, pp 186-215

Kugelmeier T, Valle RR, Guimarães MABV, Muniz JAPC, Monteiro FOB, Oliveira CA (2011) Tracking the ovarian cycle in blackand-gold howlers (Alouatta caraya) by measuring fecal steroids and observing vaginal bleeding. Int J Primatol 35:605-615

Mason GJ (2010) Species differences in response to captivity: stress, welfare and the comparative method. Trends Ecol Evol 25:713-721

Morgan KN, Tromborg CT (2007) Sources of stress in captivity. Appl Anim Behav Sci 102:262-302

Nuñez-de La Mora A, Chatterton RT, Choudhury OA, Napolitano DA, Bentley GR (2007) Childhood conditions influence adult progesterone levels. Plos Med 4:813-821

O'Neill AC, Fedigan LM, Ziegler TE (2004) Relationship between ovarian cycle phase and sexual behavior in female Japanese macaques (Macaca fuscata). Am J Phys Anthropol 125:352-362

Rangel-Negrín A, Alfaro JL, Valdez RA, Romano MC, Serio-Silva JC (2009) Stress in Yucatan Spider Monkeys: effects on environmental conditions on fecal cortisol levels in wild and captive populations. Anim Conserv 12:496-502

Sapolsky RM, Romero LM, Munck AU (2000) How do glucocorticoids influence stress response? Integrating permissive, suppressive, stimulatory, and preparative actions. Endocr Rev 21:55-89

Shideler SE, Ortuño AM, Morán FM, Moorman EA, Lasley BL (1993) Simple extraction and enzyme imunoassays for estrogen and progesterone metabolites in the feces of Macaca fascicularis during non-conceptive and conceptive ovarian cycles. Biol Reprod 48:1290-1298

Sousa MBC, Ziegler TE (1998) Diurnal variation on the excretion patterns of fecal steroids in common marmoset (Callithrix jacchus) females. Am J Primatol 46:105-117

Van Belle S (2015) Endocrinology of howler monkeys: review and directs of future research. In: Kowalewski MM, Garber PA, Cortes-Ortiz L, Urbani B, Youlatos D (eds) Howler monkeys: 
adaptive radiation, systematics, and morphology. Springer Press, pp 203-228

Van Belle S, Estrada A, Ziegler TE, Strier KB (2009) Sexual behavior across ovarian cycles in wild black howler monkeys (Alouatta pigra): male mate guarding and female mate choice. Am J Primatol 71:153-164

Wasser SK, Thomas R, Nair PP, Guidry C, Southers J, Lucas J, Wildt DE, Monfort SL (1993) Effects of dietary fibre on faecal steroid measurements in baboons (Papio cynocephalus). J Reprod Fertil 97:569-574
Wingfield JC, Sapolsky RM (2003) Reproduction and resistance to stress: when and how. J Neuroendocrinol 15:711-724

Ziegler TE, Scheffler G, Wittwer DJ, Shultz-Darken N, Snowdon CT, Abbott DA (1996) Metabolism of reproductive steroids during the ovarian cycle in two species of callitrichids, Saguinus Oedipus and Callithrix jacchus, and estimation of the ovulatory period from fecal steroids. Biol Reprod 54:91-99

Ziegler TE, Santos CV, Pissinati A, Strier KB (1997) Steroid excretion during the ovarian cycle in captive and wild muriquis, Brachyteles arachnoides. Am J Primatol 42:311-321 